\section{The compromise response: Fact or artifact?}

\author{
DENNIS F. FISHER \\ Human Engineering Laboratories, Aberdeen Proving Ground, Md. 21005
}

Two experiments were conducted to examine the effects of congruity on perceptual recognition. The first experiment attempted to replicate the findings of Bruner \& Postman (1949) with regard to compromise and dominance response types. The results failed to confirm the occurrence of compromise responses, but the dominance responses were present. Evidence is given for a hierarchical structure in the perceptual system which orders stimulus dimensions according to some predetermined criteria in order to facilitate identification. In the second experiment, when congruity was degraded, compromise responses did occur and were accounted for by a conflict in implicit set.

The now classic paper by Bruner \& Postman (1949) on the perception of incongruous stimuli, namely, reversed playing cards, showed that there were primarily two incorrect response characteristics. The first of these was the dominance response or "perceptual denial" which occurred when $S$ was presented a 6SR (six of spades, red) and reported seeing a $6 \mathrm{SB}$ or $6 \mathrm{HR}$. Such responses were said to be given because of a response bias for color or shape. The second was the compromise response or "perceptual conflict" which was evidenced by $S$ 's report of purple, brown, etc., when presented with an incongruous red card. This response type was attributed to a conflict of implicit set largely due to the lack of exposure to incongruous playing cards, that is, a conflict with expectancy. The overall result of the occurrence of the incongruous cards was a dramatic increase in the recognition times for these cards.

It took nearly two decades before anyone reexamined the findings of Bruner and Postman, using stimuli comparable to what was originally used. Lasko \& Lindauer (1968) were primarily interested in the differences in recognition times between the congruous and incongruous cards that were reported by the original study. Basically, they found that it took about five times as long to report the incongruous cards correctly as it did to report on the congruous cards. Although this finding substantiated that of Bruner and Postman, it left many other questions regarding the cause or nature of the dominance and compromise responses unanswered.

Kempen, Hermans, Klinkum, Brand, \& Verhaaren (1969) addressed themselves to the possibility that methodological artifacts accounted for the dominance and compromise responses rather than the influence of explicit and implicit set. They felt that poorly constructed stimuli (painted-over normal playing cards) added an artifact to the experiment, causing correctly seen and color labeled stimuli to be counted as incorrect responses, even though this point was specifically denied by Bruner and Postman. Instead of having normal cards painted over to make them incongruent, they had cards normal playing cards. Their contention was that in making this modification to the cards, the compromise and dominance responses would disappear. Compromise responses did not occur; however, the dominance response and longer recognition latencies for incongruent cards remained.

The present experiment was also prompted by the possibility of a methodological artifact in the original study and attempted to replicate and extend the Kempen et al findings. In addition, an examination of the differences in recognition thresholds for number, color, and suit was made. In this regard, the presence of incongruous cards should cause those dimensions associated: with congruity, namely, color and suit, to have longer recognition latencies than number.

\section{EXPERIMENT 1}

$$
\text { Subjects }
$$

Twenty-eight male U.S. Army enlisted men served as volunteers. All Ss had normal (20-20) uncorrected vision with no color deficiencies, as measured by a Bausch and Lomb Ortho-rater Color Slide F-7. All Ss reported having had prior experience with playing cards.

\section{Stimuli}

Normal playing cards were photographed and processed in positive and negative high contrast black and white Kodalith prints. Black spades, clubs, hearts, and diamonds were rephotographed directly, while white spades, clubs, hearts, and diamonds were rephotographed using a No. 50 magenta filter pack at $.4 \mathrm{sec}$ at f 8 . These processes gave exact reproduction of reds and blacks for

\section{Apparatus}

All stimuli were on $2 \times 2$ slides and were exposed to $S$ by means of a Scientific-Prototype, Model GB, printed in the "real" red and black of both types of cards. autotachistoscope at a luminance level of $4.0 \mathrm{fL}$. Lamps and timers were controlled by a uxiliary Massey-Dickinson Co. solid-state programming logic.

\section{Procedure}

The procedure used by Bruner \& Postman (1949) was followed as closely as possible. Briefly, the stimuli used were as follows: $2 \mathrm{SR}, 4 \mathrm{HB}, 6 \mathrm{SR}$, $6 \mathrm{CR}, 3 \mathrm{HB}, \mathrm{ADB}, 5 \mathrm{HR}, 7 \mathrm{SB}, 5 \mathrm{SB}$. They were arranged in the precise order given in the original experiment (p. 209). Each stimulus was presented three times at each exposure duration. The durations used were $10,30,70$, and $100 \mathrm{msec}$, with increases of 50 -msec increments up to $800 \mathrm{msec}$ (Bruner \& Postman went to $1 \mathrm{sec}$ ). If two correct successive identifications occurred, the next stimulus was presented at $10 \mathrm{msec}$ until each $S$ had received five different stimuli. Ss were not cued as to the type of stimuli they w auld receive (congruent or incongruent) and were instructed to report everything they saw.

Results and Discussion

None of the $28 \mathrm{Ss}$ gave a response that resembled the compromise response of Bruner and Postman. All color responses were black or red, and suit responses varied accordingly, giving substantiation to the occurrence of the dominance response.

In order to assess any differences that might occur in the recognition of a particular dimension, the mean recognition times (RT) for each S were found for congruent and incongruent cards with regard to color, suit, and number. These data were subjected toan analysis of variance (Butler, Kamlet, \& Monty, 1969) with stimulus type (incongruent or congruent) and dimension (color, suit, and number) as within-S variables.

The mean RTs appear in Table 1. Both main effects and the interaction were found to be significant. For congruity, $F(1,27)=8.76, p<.01$; for dimensions, $F(2,54)=8.4, p<.001$; and for the interaction of Congruity by Dimensions, $F(2,54)=4.6, p<.05$. The means in Table 1 listed for total are neither arithmetic means of the data above it nor a part of the analysis of variance; instead, they reflect the mean correct recognition times for all Ss for congruent and incongruent cards.

In short, then, these results indicate a significant effect of congruency as

Table 1

Mean (Median) Recognition Times in Milliseconds by Dimension

\begin{tabular}{lrr}
\hline & Incongruent & Congruent \\
\hline Color & $131.2(132)$ & $61.2(18.8)$ \\
Suit & $86.0(21.7)$ & $26.5(11.0)$ \\
Number & $30.2(34.6)$ & $41.6(13.8)$ \\
Total & $200.8(151.2)$ & $97.6(46.3)$ \\
\hline
\end{tabular}


well as a hierarchical ordering of the recognition process for different stimulus dimensions. This hierarchy, however, was found to differ for incongruent (number, suit, color) and congruent (suit, number, color) cards. A possible explanation for these results might be based upon the distinguishing features of the stimuli. If $S$ decided to attend to suit, he would be more likely to have correct identification sooner if it were congruent than if it were incongruent. However, in each case, $S$ would assume he was correct and attend to another dimension-number or color-as the next step toward correct identification. This, then, would account for a longer RT for number with the congruent cards and a shorter RT for the incongruent cards, because suit would have been incorrect for the latter but number would have been correct. Research efforts dealing with perceptual recognition of multidimensional stimuli varying on congruency, possibly in the choice reaction time paradigm, might provide further insight into this question.

$$
\text { EXPERMMENT } 2
$$

The absence of compromise responses in Experiment 1 could be attributed to either the improvement in the stimuli which would have made the Bruner and Postman finding an artifact or to a failure of implicit set, or the expectancy process, to be discupted by a simple "flip-flop" of the color and suit relationship. To test these possibilities, an attempt was made to increase incongruity by using additional cards made in colors other than the standard red and black. If incongruity is increased, meeting expectancy should be more difficult, causing RTs to increase and compromise responses to occur.

$$
\text { Subjects }
$$

Eight U.S. Army enlisted men served as volunteers. All So met the same criterion imposed on $\mathrm{Ss}$ in Experiment 1.

Stimuli

In addition to the normal and reversed playing cards described in Experiment 1 , cards. were
Table 2

Stimulus Sequences and Recognition Times (Milliseconds) in Experiment 2

\begin{tabular}{lrrrrr}
\hline S & AHR & 4DR & $6 S G$ & $5 C B$ & $7 S B$ \\
\hline 1 & 10 & 30 & 225 & 50 & 30 \\
\hline & 30 & 10 & 225 & 30 & 30 \\
\hline 3 & $3 H R$ & $9 S G$ & $6 D R$ & $4 H Y$ & $7 S B$ \\
\hline 4 & 10 & 10 & 10 & 150 & 30 \\
& 200 & 600 & 70 & 200 & 100 \\
\hline 5 & $3 D G$ & $6 S R$ & $8 C Y$ & $6 D R$ & $5 S B$ \\
\hline 6 & 350 & 30 & 700 & 10 & 10 \\
\hline & 500 & 25 & 800 & 10 & 10 \\
\hline 7 & $5 C Y$ & $4 H B$ & $5 S B$ & $6 D G$ & $2 S R$ \\
\hline 8 & 800 & 500 & 85 & 800 & 600 \\
\hline & 800 & 10 & 275 & 600 & 50 \\
\hline
\end{tabular}

photographed in green (No. 50 magenta, color negative base), yellow (No. 40 blue, No. 10 magenta, color negative base), and blue (No.60 yellow, No. 10 magenta, color negative base). Blue was subsequently eliminated as it could not be differentiated from black during continuous exposure.

Procedure and Apparatus

Procedure and apparatus were the same as those described in Experiment 1, except for changes of stimuli and sequences.

Results and Discussion

The stimuli and recognition times are shown in Table 2 . Immediately apparent from this table is the great discrepancy between the recognition times for the congruent and incongruent cards. The recognition times for the normal cards (52 msec) and reversed cards (203 msec) are comparable with those reported in Experiment 1. The additional cards had a mean recognition time of $483 \mathrm{msec}$, indicating that a higher degree of incongruity had a more negative effect on the recognition processes.

Of much greater interest was the fact that compromise responses did occur. Some examples of these responses are as follows: $S 2$-in response to $6 \mathrm{SG}-6 \mathrm{~S}$ blue (10-150 msec), purple (150-200), correct recognition at 225 msec. S 4-in response to $4 \mathrm{HY}-4 \mathrm{SR}$ (100-150), correct recognition at $200 \mathrm{msec}$. S 5-in response to $8 \mathrm{CY}-8 \mathrm{CR}(10-650), 8 \mathrm{C}$ blue $(650)$, correct recognition at 700 msec. S 6-in response to $3 D G-3 D R$ $(30-400), \quad 3 D R$ with some green (450 msec), correct recognition at 500 msec. S 6-in response to 8CY-8CR (350-750), 8CG (750-800), correct recognition at $800 \mathrm{msec}$. S 7-in response to $5 \mathrm{CY}-5 \mathrm{C}$ dark green $(250), 5 \mathrm{H}$ reddish $(300-600) 5 \mathrm{C}$ blue (600-750), correct recognition at $800 \mathrm{msec}$. S 8-in response to 5CY-5CR (200-700), 5CR with some yellow in it $(700-750)$, correct recognition at $800 \mathrm{msec}$.

It should be noted that no compromise response was elicited by either the normal or the reversed playing cards. A lack of complete color development caused by the brief exposure durations might, in part, account for some of these responses; however, the failure of similar types of responses to red stimuli suggest that most of the causality must be placed upon a conflict of implicit set or the failure on the perceptual level to meet expectancy. To account for the data, it must be assumed that simple color reversals were made with relative ease and caused little conflict, while a higher degree of incongruity led to a conflict in the perceptual and subsequent response processes.

\section{REFERENCES}

BRUNER, J. S. \& POSTMAN, L. On the perception of incongruity: A paradigm. Journal of Personality, 1949, 1, 206-223. BUTLER, D. H., KAMLET, A. S., \& MONTY, R. A. A multi-purpose analysis of variance FORTRAN IV computer program. Psychonomic Monograph Supplement. 1969, 2(16, Whole No. 32) 301-319.

KEMPEN, G., HERMANS, B., KLINKUM, A. BRAND, M., \& VERHAAREN, F The word-frequency effect and incongruity perception: Methodological artifacts? Perception \& Psychophysics, 1969, 5, 161-162.

LASKO, W. J.. JR., LINDAUER, M. S. Experience with congruity in the perception of incongruity. Psychonomic Science, 1968, 12, 59 . 